pp. $44-59$

\title{
Human Resources Management Effectiveness and the Role of Quality Management: Empirical Study in Jordanian Pharmaceutical Companies
}

Submitted 09/04/20, $1^{\text {st }}$ revision 11/05/20, $2^{\text {nd }}$ revision 11/07/20, accepted 15/08/20

\author{
Hisham Abdul Kareem Shaheen ${ }^{1}$, Lama Ismail Mohammad Ahmad ${ }^{2}$, Amer \\ Saadi Kallel Shakkour ${ }^{3}$, Reem Khaled Matahen ${ }^{4}$, \\ Salwa Abdul Fattah Talab Al Azzeh ${ }^{5}$
}

\begin{abstract}
:
Purpose: This paper aims to understand the role of Quality Management and the effectiveness of Human Resource Management.

Design/Methodology/Approach: Both secondary and primary research has been carried out in this study. This paper reviewed all the literature applicable to HRM and QM activities and their application in various fields. The emphasis of the review is on the implementation, the effect on organizational performance, and the metrics encouraged for adopting an organization of practice, particularly of Jordan's pharmaceutical companies.

Findings: It has been found that Jordanian pharmaceutical companies understood the advantages of QM activities and believe they will accomplish their goals by using that strategy. Nonetheless, most companies do not take HRM and QM practices because these activities' effectiveness lacks defined reasons and less severe outcomes. Therefore, this paper presents the authors' basic understanding of the relationship between the quality management of human resources and the overall quality control and their effect on company sustainability in Jordan's pharmaceutical companies.

Practical Implications: The study seeks to provide a clear understanding of the application of company management standards and procedures.

Originality/Value: The research is the result of authors' individual effort. All the ideas used in this paper from other colleagues are properly cited and acknowledged.
\end{abstract}

Keywords: QM, effectiveness of HRM, organizational performance, implementation.

JEL code: $M 11$.

Paper type: Research study.

\footnotetext{
${ }^{1}$ Instructor, Amman Training College, Business School, UNRWA, Amman, Jordan, e-mail: hisham_shaheen2003@yahoo.com

${ }^{2}$ Instructor, as in 1, e-mail: Lomi2006@yahoo.com

${ }^{3}$ Assistant Professor, Al Hussein Bin Talal University, Accounting and Finance Department, Ma'an, Jordan, e-mail: Amer_shkor@yahoo.com

${ }^{4}$ Assistant Professor, Iman Abdulrahman Bin Faisal University, Saudi Arabia, e-mail: rkmatahen@iau.edu.sa

${ }^{5}$ Instructor, as in 1, e-mail: Sawaazzeh1972@gmail.com
} 


\section{Introduction}

Any company is more competitive and demanding at a certain age, characterized by rapid and continuous change. To be at the top of market competition, it is important to create quantifiable standards or acceptable management techniques. Nonetheless, it cannot be possible to provide quality services without human productivity. Literature reveals the possible basis for development and a company's performance or new projects known as human capital (Ahammad, Glaister, and Gomes, 2020). They claimed that workers must accept rational judgment in evolving and uncertain conditions, such as competencies, attitudes, and mental agility. This term was illustrated extensively in Human Resource Management (HRM) literature. HRM works beyond its limits to supply highly skilled recruitment and selection candidates and generally assess how well they are informed of its goals. This ensures that these aspects should be investor-friendly and versatile to meet their individual needs (Ismail, Abdelrahman, and Majid, 2018).

Companies paying attention to the quality of their processes in the global business world are primarily compensated, and companies must continually enhance the quality of their organizations' goods and services to thrive on a challenging competitive market. The management is asked to find ways of enhancing their customer service. The business world has luckily been able to identify many ways in which their individual companies can accomplish and improve efficiency (Alomari, 2020). While different organizations pray for variables, they all have one specific method, which is Quality Management (QM). Researchers have different definitions of QM, but everyone accepts that it can increase the quality of goods and services based on proper QM implementation, enhance the level of efficiency of the Company, and minimize costs, thereby increasing the competitive advantage of the Company on the global market (Aburumman, Salleh, Omar, and Abadi, 2020).

Apart from these previous studies, everybody agrees that QM is a method to enhance an organization's efficiency and versatility as an entire entity, i.e., basically, a way to coordinate and involve the entire business, each person at each level or department. This includes remembering each person in the organization and realizing that each operation (small or large) matters for every company that strives for quality improvement (Pham, 2020).

Human resources and quality management have been identified as 'modern' approaches that have drawn an infinite amount of attention from academics and practitioners. Both terms are regarded as an essential philosophy of management that underpins the organizational effort to satisfy customers (Yu, Chavez, Feng, Wong, and Fynes, 2020). The purpose of this paper is to view HRM as the right mix for quality management (QM), respectively. Moreover, this paper aims to analyze and evaluate the practices of HRM and QM in Pharmaceutical Companies in Jordan. 


\section{Literature Review}

\subsection{Human Resource Management}

Human Resource Management is one of the most critical activities of any corporate leader. It includes people and arranging things around them. HRM is characterized as a systematic and consistent approach to managing the most valued assets of an organization, namely the people who commit to achieving its goals individually and together. HRM is responsible, according to research, for schedule, coordinate, manage and monitor recruitment, growth, and resources to achieve individual and social goals (Ana, 2015).

HRM is a management viewpoint that suggests that an interconnected set of personnel policies must accompany the organizational approach. HRM is a collection of loosely connected theories, principles, and strategies, together with underpinning the principle that optimizing the use of human capital in any enterprise is essential for sustaining and improving productivity in an environment where those who are not performing effectively cannot survive (Ogbeibu, Emelifeonwu, Senadjki, Gaskin, and Kaivo-oja, 2020).

By creating a plan that addresses the transition, the HR Department will play an important role in the change process. The implementation of the new and creative ways of management is also correlated with HRM. Quality management concern is not new, but the quality has recently been used as an important element in searching for competitive advantage (El-Dirani, Houssein, and Hejase, 2020).

\subsection{Quality Management}

To develop modern governance, the introduction of quality management (QM) has played an important role. Quality management (QM) means optimizing and integrating all roles and processes of an organization to provide enthusiastic clients through an ongoing improvement cycle. QM is described as an employee-driven management system that continually aims to enhance customer satisfaction at lower costs. To investigate QM activities' impact on the product's efficiency, literature created a QM model (Evstratova, Kabanova, Vetrova, Palehova, and Kataeva, 2019). Research has shown that quality practices can be divided into nine dimensions:

- employee engagement,

- shared vision,

- customer attention,

- team use,

- staff education,

- collaboration with suppliers,

- use of benchmarking,

- automated manufacturing processes,

- the practice of just-in-time. 
QM can be defined as a set of methods to reduce or eliminate variations in production or distribution processes to improve performance, reliability, and quality (Sharma and Sindhu, 2016).

The old concept is reactive, structured to address quality issues after they emerge, and the new concept proactively incorporates quality in the product and process design. Quality management (QM) for individuals, groups of people, and the overall organization is continuous improvement (Mendoza, Popa, D'Aponte, Gualtieri, and Azapagic, 2019). QM is concerned with improving the way things are done over the life of the company. People need to know what to do, how to do it, have the right tools, and assess progress and the actual success level to strengthen the process (Mousa and Othman, 2020).

\subsection{The Role of QM and the Effectiveness of HRM}

The complete quality management or QM is all company activities to ensure that the organization meets its customers' needs. Continuous assessment and enhancement of how well the company meets the customer's needs require quality control. To integrate quality values into an organization's culture and that all the operations are geared towards customer satisfaction, QM employs efficient communication methods (Othman, Ghani, and Choon, 2019).

Quality management is an ongoing strategy for success; a company aims to achieve by satisfying its clients. To achieve overall customer satisfaction, all company members work together to enhance product quality, service, and culture within the organization. The ways to achieve full quality control in the organization must be advised (Donate, Ruiz-Monterrubio, Pablo, and Peña, 2019).

Quality management makes sure that the company delivers the products and services that are the exception in quality. For any product, the quality is based on three-factor that includes performance, durability, and reliability. The quality management and its process are crucial for the company based on differentiating its competitors. The tools that are being used in quality management are being used to have a change in the system and the processes which can yield the premium quality products for the company. The methods for quality management include Total quality management and Six Sigma that have one goal that is to deliver high-quality products in the market. It is essential to meet the criteria of quality in the market to exceed the customers' needs and demands and attain a greater satisfaction level. The customers should be satisfied with the quality of the product to gain their loyalty and trust. Businesses grow in the market only when the products have better quality than the substitute or alternate products.

To take the business to the pinnacle of success, it is essential to ensure that it fulfills its needs and demands. The quality management marks the products with high quality and service by eliminating any defects and issues and bringing the innovation 
in the products with time. By ignoring quality management, the company might save some money, but in the long run, this technique fails as the products and service lose their customers in the market.

With a global business, organizations have developed a new perspective for quality and market survival, the management of human resources must ensure that the quality of the products and services is in line with customer requirements (ALHazmi and Alkhateeb, 2020). The HR role should, therefore, create a QM framework to direct its operations. A model of this sort should be made up of four key tasks: writing an HR vision statement, contrasting HR practices with leading QM organizations, define consumer needs at home and abroad, and refurbishing work processes (Donate, Ruiz-Monterrubio, Pablo, and Peña, 2019).

Quality management $(\mathrm{QM})$ is now widely recognized as a significant breakthrough in management. However, most of the contributions to the TQM analytics and its activities were made by people in operations management (Saffar and Obeidat, 2020). Without a doubt, it has created a controversy about the so-called "hard" production-oriented elements of QM compared to their "softer" characteristics in human resource management. In other words, less attention was given to human resources management concerns such as effective monitoring methods, compensation/payment schemes, coordination, labor relations, and the consequences for different management functions (Abbas, 2020).

In this context, external and internal organizational focus make the strategic intention behind QM clear. More generally, QM and HRM are strategic for their large organization, implying "specific policies and activities should be linked to an overall management strategy." (Abbas and Abbas, 2020). Four functional areas can be discussed in more depth regarding the relationship between HRM and QM: job management, preparation, hiring, performance evaluation and remuneration, training, and development. HRM and $\mathrm{QM}$ are closely related in terms of job organization (Albejaidi, 2018).

Services industries primarily follow the soft side of QM while the hard side is applied to manufacturing industries. The problem with this definition of "hard" and "soft" QM is that most organizations, particularly in manufacturing industries, do not effectively combine these two sections due to their desire to meet the timetable. Research suggests that 80 percent of the world's jobs have switched from production to service sectors, according to the United States and other highly developed countries (Badea and Apostol, 2020).

All that can be said is that quality improvement can be accomplished only through human activities within an organization, HRM is the methodology embraced through organizations, and HRM is characterized as a strategic and coherent approach to managing the most valued assets of an organization, i.e., people/humans who contribute to the achievement both individually and collectively (Zhang et al., 2016). 
People are the company's main asset, and organizational success is largely based on the HRM experience. HR would therefore have a direct impact on an organization's efficiency if enough HR activities and procedures are created and implemented effectively and the HR effectiveness is impacted by Quality Management (Chuševè, Nygård, Vaičiūte, Daunys, and Zaiko, 2016).

\subsection{QM and HRM in Jordanian Pharmaceutical Companies}

In Jordanian Pharmaceutical Companies, QM strategies have modified managers' perceptions and beliefs about managers' positions. In fact, clients' perceptions of the HRM profession have shifted. The goals of business organizations have historically been limited to profitability and income. Therefore, consumers and workers were given low priority by stakeholders. The company aims and the quality approach to HRM is, however, to optimize customer loyalty and to increase market share in the Pharmaceutical businesses of Jordan (Lenk et al., 2018). The benefits generated by teams and agile workplaces, task appraisal, and role redesign are the subject of both HRM and QM. QM seeks to define and remove bottlenecks and obsolete work processes by scrutinizing job material and structures and streamlining procedures in the Jordanian Pharmaceutical Companies (Lenk et al., 2018).

To this end, HR managers and specialists must "commit programs and resources, which improve the organization" to become motivated. Human resources planning and hiring have a strategic role to play in ensuring that individuals whose goals and principles are aligned with the QM ideology and whose characteristics suggest that they are suited to a versatile, team-based environment in Jordanian Pharmaceutical Companies (Al-Hazmia, 2020).

In this hiring and choosing process, QM allows HR professionals to work closely with management, where HRM plays a more decentralized and strategic role. This partnership is important to ensure that workers are adequately trained in QM technology and correctly monitored and rewarded (Schnitzbauer, 2020). Also, several QM supporters point to the risk of performance appraisal that leads workers to get away from proper TQM conduct. It also underlines the vital position of HRM to ensure that the HR program is QM compliant so that workers can be compensated for their good actions for Jordanian Pharmaceutical Companies (Nigam and Prakash, 2016).

A pharmaceutical company must accept both external and internal, resource-based, and relation-based views to succeed. This will affect the role of HRM in the strategy phase of an organization. On the one hand, organizations will determine whether HRM plays a practical strategic role by being sensitive to organizational approaches that adhere to the corresponding HRM model ( $\mathrm{Yu}, \mathrm{He}$, and $\mathrm{Lu}, 2016$ ). Otherwise, underlined by the resource-based model of SHRM, organizations may prefer HRM to take a constructive, all-embracing position to become highly integrative in corporate strategy. This choice will decide to what degree QM gives HRM the 
chance to play a more strategic role in the company in Jordanian Pharmaceutical Companies (Sawaean and Ali, 2020).

After all, QM is influenced at all rates by the strategy process. Concerning HRM, this influences both the structure of a company and its working organization, hiring and planning; performance evaluation and remuneration; and the policies and procedures for training and development. Organizations that do not follow the weaker side of the QM lose traction and confidence in their initiatives (Nicholson, Smith, McCoy, Carty, and Yip, 2020). As such, Pharmaceutical companies in Jordan can exercise SHRM effectively at a reactive, functional level, and this can offer some competitive advantage. Instead, QM requires or otherwise provides companies the chance to take on a more constructive, inclusive role at the corporate, company, and functional level in the strategy process. QM is also listed as a competitive advantage source for a product (Devine, Broderick, Harris, Wu, and Hilfiker, 2016).

\section{Methodology}

Research methodology is essential while conducting the research. It helps to provide a more structured approach to the whole study and helps to outline a plan of action. The research methodology outlines how the research is conducted, what approach is followed, the philosophy of research is adapted, what was the target population, what was the data collection type and instrument; it helps in selecting data analysis tools and identify variables.

This research is descriptive than quantitative in its entirety. This includes gathering data as a literature survey, questionnaire survey, and asking questions from other chosen HR managers like the organization's case study managers. The evidence provided in this research has been obtained from different sources on the topic in question. This work also uses books, papers, web sites, and articles on the management of human resources, total quality control, and HRM's role in QM's effective execution. There was no systematic analysis, but the knowledge was gathered using secondary sources. Personal opinions and observations shall be kept at a minimum. The literature on the management of human resources and the role of QM in HR's performance are discussed.

\subsection{Research Approach}

Two types of research approaches are widely used in research studies are as follows:

The qualitative approach uses non-numeric data and seeks to understand the underlying motivations and reasons to uncover trends. Qualitative research is most helpful in small-scale studies where the number of participants is small, and the research is conducted on focus groups group discussions, individual in-depth interview sessions, and others. 
Quantitative research is mostly used when the study's overall scope is broad, and the number of participants is large. The study relies on numeric statistical data to produce a set of generalized results that reflect a sample size. These results can clearly portray the wider population interests. Most of the quantitative studies' data are present in tabular forms, and the analyses and findings are completed descriptively. This study follows a quantitative research approach.

\section{Research Methodology}

The research follows the objectivism research philosophy. Objectivism is defined as a notion that the research objectives already exist in the real world, and there is a need to add more information to the already established knowledge to produce complete information. Objectivism is ontology philosophy and is articulated by scientific philosophy widely known as critical realism. The target population was employees working in Jordan pharmaceutical sector. Primary data collection has been used for this research as it is considered more reliable. Likert scale was used for data collection. The Likert scale-based questionnaire consists of various closeended questions, and the participants' responses are given on a scale of 1 to 5 . The questionnaire was distributed to the employees where they were asked to fill it without having any biased opinion about the human resource management of the company.

The questionnaire research method has a less costly and efficient and quick way to collect the information and data from a; large sample of people (Thurber et al., 2020). The data was collected quickly because there was no need to be present when the participants completed the questionnaire.

With this research, the questionnaire has proved to be an effective way of analyzing employees' behavior and attitudes towards human resource management and collecting their opinions and intentions efficiently than any other method. The question on the questionnaire was both open-ended and closed questions. In openended, the sample population had the opportunity to represent their thought and ideas concerning human resource management; however, the closed questions were based on the employees' satisfaction with the conduction of human resource management activities. It enabled us to collect the qualitative and quantitative data of the company.

\subsection{Data Analysis Technique}

The data analysis can be defined as the process based on transforming the collected data and modeling it to gather useful information and make the decisions accordingly. The main purpose of data analysis is to extract the information from the collected data and make the company's decisions as per the data analysis (Pietilä et al., 2019). The data analysis process helps gather the information through proper application and tools that can help the researchers explore the data and determine its 
pattern. Based on the information and the data collected, the information can be gathered to conclude.

The company needs to gather the data and use it to make decisions for the future as it can help provide the information related to risk and dangers and analyze the decisions accordingly. It can help the company find the reasons for the business that is not generating enough revenue and making a plan and activities to eliminate those factors. In this research, data analysis has been conducted using text analysis, qualitative analysis, and statistical analysis. Statistical data analysis has been conducted using SPSS. The data was collected from 100 participants that have been working in a pharmaceutical/company in Jordan.

The statistical analysis has helped the research to show what happens by using the past data in the dashboard form. This analysis method included collecting data, analysis, interpretation, presentation of the results, and modeling the data together with the information. The statistics used in this research are in interquartile range and standard deviation compared to the upper quartile, and lower quartile ranges are different from them. Some of the data lie in the upper quartile, while some in the lower quartile. The standard deviation is based on determining the average difference in each data point and their mean (Greckhamer et al., 2018). If all the points lie close to the mean that it indicates the lower standard deviation, there is little difference in the values. However, the large standard deviation shows that there is much difference in the obtained values.

\subsection{Analysis and Results}

The majority of the study respondents were almost $60 \%$, and the female participants stood at almost $40 \%$. While most of the female participants were 40 years and older, most of the female participants represented almost 19 percent of the sample size. Simultaneously, almost $70 \%$ of the total respondents hold a bachelor's degree, whereas only $14 \%$ had post-graduate degrees in their respective fields. This suggests that hiring is done based on education and experience, most of the employee with post graduate degree worked in id level management while the majority of the employees who had bachelor's degrees were working in lower managerial levels. 100 employees had participated in the research, and the sample size had employees belonging to every operational level of the organization.

The study seeks to develop an understanding of human resources and the effectiveness of quality management. The study focused on three characteristics on narrowing down the scope of the study. The areas under focus are employee performance, employee retention, and employee engagement. Table 1 shows the designated value of VIF for an independent variable that is less than 10. Tolerance is more than 0-20 an indicates that the problem of collinearity is in relationship with these variables. Therefore, it can be seen that the measures are selected for assessing 
different independent variables that do not reflect any multicollinearity. This suggests that there is an important association between HRM and QM practices.

Table 1. Testing for Collinearity

\begin{tabular}{|l|l|l|}
\hline \multirow{2}{*}{ Model Management } & Statistics of Collenearity \\
\cline { 2 - 3 } & Tolerance & VIF \\
\hline $\begin{array}{l}\text { Top } \\
\text { Commitments }\end{array}$ & 0556 & 1.796 \\
\hline Customer Focus & 0.475 & 2.098 \\
\hline Employee Engagements & 0.585 & 1.714 \\
\hline Continuous Improvements & 0.499 & 1.999 \\
\hline
\end{tabular}

Source: Own study.

Table 2 shows the simple regression for Quality Management on Human resources management effectiveness,

Table 2. Simple regression

\begin{tabular}{|l|l|l|l|l|l|l|l|l|}
\hline $\begin{array}{l}\text { Independent } \\
\text { variables }\end{array}$ & Sig, & $\mathrm{t}$ & Beta & $\mathrm{F}$ & $\mathrm{df}$ & $\mathrm{R} 2$ & $\mathrm{R}$ & $\begin{array}{l}\text { Statistical } \\
\text { decisions }\end{array}$ \\
\hline $\begin{array}{l}\text { Quality } \\
\text { Management }\end{array}$ & 0 & 21.520 & 0.730 & 463.137 & 404 & 0.532 & 0.730 & Rejected \\
\hline
\end{tabular}

Source: Own study.

Table 2 portrays the implementation of Quality management that has an immense impact on the complete human resource management effectiveness. The estimated value of R2 is 0.532 that suggest that the implementation of Quality Management, which explains almost $53 \%$ variation, has occurred in in overall human resource management effectiveness. The higher value of $\mathrm{R}(0.730)$ suggests that the current model has a suitable correlation. This implies that the null hypothesis has been rejected and the alternate hypotheses that quality management implementation on human resource management effectiveness can be adopted instead. The results suggest that quality management dimension can have great bearing on the overall effectiveness of human resource management practices. This explains the interest of the Jordanian pharmaceutical companies to implement quality management techniques and philosophies to ensure the overall effectiveness of utilizing human resources.

The research takes analysis other steps by investigating the influence of every quality management dimensions and the overall human resource management practices. Stepwise and multiple regression can be utilized as suggested in the following Table 3 to show results of regression.

It has been highlighted in Table 3 that the quality management implementation on Human Resource Management effectiveness can have a significant impact on the overall business operations. Simultaneously, the multiple regression results indicate that top management or upper-level organizational employees do not significantly 
impact human resource management effectiveness. It has also been observed that employee engagement and continuous improvements can have a significant impact on HRM effectiveness. Simultaneously, the results suggest that employee engagement should be the priority, followed by customer focus and, finally, continuous improvement.

Table 3. Impact of Quality management dimensions on Human resource management effectiveness using Multiple regression

\begin{tabular}{|l|l|l|l|l|l|}
\hline $\begin{array}{l}\text { Quality Management } \\
\text { Dimensions }\end{array}$ & Sig. & B & t & Beta & $\begin{array}{l}\text { Statistical } \\
\text { Decision }\end{array}$ \\
\hline Customer focus & 0.000 & 0.260 & 5.314 & 0.257 & Rejected \\
\hline Continuous improvements & 0.000 & 0.247 & 5.434 & 0.256 & Rejected \\
\hline Top management commitment & 0.806 & 0.010 & 0.243 & 0.010 & Rejected \\
\hline Employee engagement & 0.000 & 0.324 & 7.991 & 0.349 & Rejected \\
\hline
\end{tabular}

Source: Own study.

\section{Discussion}

During the complex changing market climate affected by globalization, businesses focus more on the growth and enhancement of their management practices. It is seen to be an essential element for business success to identify and respond properly to changes in the environment by choosing the convenient strategy and management approach (Jonathan, Mafini, \& Bhadury, 2019). Quality Management (QM), which has gained attention in the last 3 decades, is operational management practice. Cases cited in the literature illustrate that many organizations'organizations' implementation of the QM principles was successful (Alomari, 2020).

Different measures and dimensions of management quality were analyzed in the research while conducting primary data collection and quantitative analysis. The researchers suggest that the businesses need to make employee engagement the priority; the Jordanian pharmaceutical sector needs to improve employee engagement and an effectiveness erasure to improve HRM. At the same time, the businesses need to focus on the customer when they have improved overall employee engagements and then move towards continuous improvements.

HRM is another crucial organizational management activity that tackles organizations'organizations' most valuable tool. Their position in enhancing the results, securing and cultivating employee talents, and enhancing collaboration to support corporate growth has become more important (Holmgreen, 2020). Managers are working on behalf of people who need effective HRM, so HRM activities should be aligned with the organization's overall plan to ensure efficient human use and efficiency for Pharmaceutical companies in Jordan (Aragon and Garcia, 2015).

When quality management is achieved, the task of human resources effectiveness is fulfilled in any organization. In the case of an evaluation of the organization's 
organization's success, both principles are inseparable (Wong, 2015). The main explanation for establishing both divisions within the company is the need to ensure customer loyalty by providing quality services or goods. A company's future and strong market position hinge on its customers' satisfaction (Ismail, Abdelrahman, \& Majid, 2018). A target that any business aims to achieve is customer satisfaction. A company's reputation depends on how well it serves its clients (Persson, Persson, \& Sam, 2016).

\section{Conclusion}

No single theoretical formalization of quality management and HRM exists; researches provide the fundamental assumptions as a discipline and management philosophy that institutionalize planned and ongoing enhancement and presumes that quality is the product of all activities within a company; that all the functions and all the employees need to be involved in the process of progression; that organizations require both quality systems and quality culture.

\section{Limitations}

Although the secondary data was used as a reference in this study, the exact purpose of the analysis was not fulfilled in all sources. Moreover, since some secondary data contained unpublished literature, it could not be verified without being examined by peers. A secondary data problem may be that bias might have crept in during the obtaining of data that does not provide any exposure but may impact this research inadvertently. It does not always help to use secondary data for these specific purposes, but rather to dig into previous studies' intent a little deeper to obtain a broader perspective on them.

As urging the participants to take part in the survey is quite different in the secondary research method, it is essential to make sure that the obtained results are accurate (De Block and Vis, 2019). During the sampling selection decisions, the sampling bias can occur, which means some of the participants have more chances to take part in the survey while some do not have a chance to attend the survey. As a result, it can lead to obtaining unreliable results.

Self-selection is hard to eliminate from the survey and difficult to manage. The participants taking part in the survey should be taking part voluntarily and not being forced by anyone. The researchers should make sure that they keep the participants anonymous and do not disclose it in any way; however, the collected information and the gathered data should not be used for any other means and purpose (Greckhamer et al., 2018). The researchers should make a form based on ethics and law and should be signed by the participants and the researchers so that both parties can be sure of maintaining privacy. 
During the survey, it is essential to follow all the ethical laws and regulations and conduct the survey when the employees are not working or have free time as it can disturb them and divert their attention from the work that can affect their performance. The survey should be conducted with the permission of the company owners and the managers, so they have an idea about the participation of the employees.

\section{References:}

Abbas, J. 2020. Impact of total quality management on corporate sustainability through the mediating effect of knowledge management. Journal of Cleaner Production, 244, 118806. https://sciencedirect.com/science/article/pii/s0959652619336765.

Abbas, J., Abbas, J. 2020. Impact of total quality management on corporate green performance through the mediating role of corporate social responsibility. Journal of Cleaner Production, 242, 118458. https://sciencedirect.com/science/article/pii/s0959652619333281.

Aburumman, O., Salleh, A.M., Omar, K., Abadi, M. 2020. The impact of human resource management practices and career satisfaction on employee's turnover intention. Management Science Letters, 10(3), 641-652. http://growingscience.com/msl/vol10/msl 2019 267.pdf.

Ahammad, M.F., Glaister, K.W., Gomes, E. 2020. Strategic agility and human resource management. Human Resource Management Review, 30(1), 100700. https://sciencedirect.com/science/article/pii/s1053482218307435.

Albejaidi, F.M. 2018. An Investigation into the Challenges Towards Implementation of Total Quality Management Under the Saudi Healthcare National Transformation Program-2020. Journal of Health, Medicine and Nursing, 46, 96-107. https://iiste.org/journals/index.php/jhmn/article/download/40874/42030.

AL-Hazmi, N.M., Alkhateeb, T.T. 2020. Obstacles to implementing total quality management in Saudi Arabia marketing tourism Services. Management Science Letters, 10(3), 507-514. http://growingscience.com/msl/vol10/msl_2019_282.pdf.

Al-Hazmia, N.M. 2020. A study on the dimensions of the quality of tourism services in the Kingdom of Saudi Arabia. Management Science Letters, 10(5), 1115-1120. http://growingscience.com/msl/vol10/msl_2019_313.pdf.

Alomari, Z.S. 2020. Does human capital moderate the relationship between strategic thinking and strategic human resource management. Management Science Letters, 10(3), 565-574. http://growingscience.com/msl/vol10/msl_2019_276.pdf.

Ana, B.C. 2015. Human Resources Management and Quality of Life Human Resources of SMEs. Annals - Economy Series, 1, 322-325. https://ideas.repec.org/a/cbu/jrnlec/y2015v6specialp322-325.html.

Aragon, T.J., Garcia, B.A. 2015. Designing a learning health organization for collective impact. Journal of Public Health Management and Practice, 21. https://ncbi.nlm.nih.gov/pmc/articles/pmc4243793.

Badea, O., Apostol, E.N. 2020. Forest science innovation for sustainable forest management, improvement of human welfare, and quality of life under global environmental changes. Science of The Total Environment, 701, 134429. https://sciencedirect.com/science/article/pii/s0048969719344201.

Chuševè, R., Nygård, H., Vaičiūtè, D., Daunys, D., Zaiko, A. 2016. Application of signal detection theory approach for setting thresholds in benthic quality assessments. 
Ecological Indicators, 60, 420-427.

https://sciencedirect.com/science/article/pii/s1470160x15004033.

De Block, D., Vis, B., 2019. Addressing the challenges related to transforming qualitative into quantitative data in qualitative comparative analysis. Journal of Mixed Methods Research, 13(4), 503-535.

Devine, T., Broderick, J., Harris, L.M., Wu, H., Hilfiker, S.W. 2016. Making Quality Health Websites a National Public Health Priority: Toward Quality Standards. Journal of Medical Internet Research, 18(8). https://jmir.org/2016/8/e211.

Donate, M.J., Ruiz-Monterrubio, E., Pablo, J.D., Peña, I. 2019. Total quality management and high-performance work systems for social capital development. Journal of Intellectual Capital. https://emerald.com/insight/content/doi/10.1108/jic-07-20180116/full/html.

El-Dirani, A., Houssein, M.M., Hejase, H.J. 2020. An Exploratory Study of the Role of Human Resources Management in the Process of Change. Open Journal of Business and Management, 8(1), 156-174. https://scirp.org/journal/paperinformation.aspx?paperid=97169.

Evstratova, T.A., Kabanova, E.E., Vetrova, E.A., Palehova, P.V., Kataeva, V. 2019. Formation of Personnel Potential through Development of Human Resource for Supply Chain Managements on the Example of Training Program of Government. International Journal of Supply Chain Management, 8(6), 884-892. https://ojs.excelingtech.co.uk/index.php/ijscm/article/view/4183.

Greckhamer, T., Furnari, S., Fiss, P.C. and Aguilera, R.V., (2018). Studying configurations with qualitative comparative analysis: Best practices in strategy and organization research. Strategic Organization, 16(4), pp.482-495.

Holmgreen, L.L. 2020. Leadership identities: Whose construction? Text \& Talk, 40(1), 5-28. https://vbn.aau.dk/da/publications/leadership-identities-whose-construction.

Ismail, A.I., Abdelrahman, S.E., Majid, A.H. 2018. Closing Strategic Human Resource Management Research Lacunas with Mediating Role of Employee Creativity. Academy of Strategic Management Journal, 17(1), 1. https://abacademies.org/articles/closing-strategic-human-resource-managementresearch-lacunas-with-mediating-role-of-employee-creativity-7035.html.

Jonathan, E.C., Mafini, C., Bhadury, J. 2019. Risk Management in Strategic Sourcing: An African Perspective. International Journal of Supply Chain Management, 8(5), 119135. http://ojs.excelingtech.co.uk/index.php/ijscm/article/view/2694.

Lenk, E.J., Redekop, W.K., Luyendijk, M., Fitzpatrick, C., Niessen, L.W., Stolk, W.A., Severens, J.L. 2018. Socioeconomic benefit to individuals of achieving 2020 targets for four neglected tropical diseases controlled/eliminated by innovative and intensified disease management: Human African trypanosomiasis, leprosy, visceral leishmaniasis, Chagas disease. PLOS Neglected Tropical Diseases, 12(3). https://journals.plos.org/plosntds/article?id=10.1371/journal.pntd.0006250.

Mendoza, J.M., Popa, S.A., D'Aponte, F., Gualtieri, D., Azapagic, A. 2019. Improving resource efficiency and environmental impacts through novel design and manufacturing of disposable baby diapers. Journal of Cleaner Production, 210, 916928. https://sciencedirect.com/science/article/pii/s0959652618334462.

Mousa, S.K., Othman, M. 2020. The impact of green human resource management practices on sustainable performance in healthcare organisations: A conceptual framework. Journal of Cleaner Production, 243, 118595. https://sciencedirect.com/science/article/pii/s0959652619334651. 
Nicholson, K.J., Smith, K.J., McCoy, K.L., Carty, S.E., Yip, L. 2020. A comparative costutility analysis of postoperative calcium supplementation strategies used in the current management of hypocalcemia. Surgery, 167(1), 137-143. https://ncbi.nlm.nih.gov/pubmed/31515122.

Nigam, K., Prakash, K. 2016. Quasi Experimental Non Randomized Study on Effectiveness of Instructional Strategy on Knowledge, Practice and Quality of Life of Head and Neck Cancer Patients Receiving Radiotherapy in Selected Cancer Research Institute, Uttarakhand. Journal of Nuclear Medicine and Radiation Therapy, 7(6), 17. Retrieved 4 30, 2020 https://omicsonline.org/peer-reviewed/quasi-experimentalnon-randomized-study-on-effectiveness-of-instructional-strategy-on-knowledgepractice-and-quality-of-life-of-he-81846.html.

Ogbeibu, S., Emelifeonwu, J.C., Senadjki, A., Gaskin, J., Kaivooja, J. 2020. Technological turbulence and greening of team creativity, product innovation, and human resource management: Implications for sustainability. Journal of Cleaner Production, 244, 118703. https://sciencedirect.com/science/article/pii/s0959652619335735.

Othman, I., Ghani, S.N., Choon, S.W. 2019. The Total Quality Management (TQM) journey of Malaysian building contractors. Ain Shams Engineering Journal. https://sciencedirect.com/science/article/pii/s209044791930156x.

Persson, L., Persson, Å., Sam, C. 2016. Implementation of the Strategic Approach to International Chemicals Management in Cambodia: effects of regime design. International Environmental Agreements-politics Law and Economics, 16(1), 1-20. https://link.springer.com/article/10.1007/s10784-014-9254-5.

Pham, H.D. 2020. Impact of human resource management practices on enterprises' competitive advantages and business performance: Evidence from telecommunication industry. Management Science Letters, 10(4), 721-732. http://growingscience.com/msl/vol10/msl 2019 308.pdf.

Pietilä, S., Suomi, T., Aakko, J. and Elo, L.L., (2019). A data analysis protocol for quantitative data-independent acquisition proteomics. In Functional Proteomics (pp. 455-465). Humana Press, New York, NY.

Saffar, N.A., Obeidat, A.M. 2020. The effect of total quality management practices on employee performance: The moderating role of knowledge sharing. Management Science Letters, 10(1), 77-90. http://growingscience.com/msl/vol10/msl_20192227.pdf.

Sawaean, F.A., Ali, K.A. 2020. The mediation effect of TQM practices on the relationship between entrepreneurial leadership and organizational performance of SMEs in Kuwait. Management Science Letters, 10(4), 789-800. http://growingscience.com/msl/vol10/msl_2019_301.pdf.

Schnitzbauer, A.A. 2020. Author response to: Beyond the scalpel - mortality after liver surgery in patients with liver metastases - time to rethink the indications: Total quality control and just culture for oncologic therapies urgently required! British Journal of Surgery, 107(1), 149-150. https://bjssjournals.onlinelibrary.wiley.com/doi/abs/10.1002/bjs.11411?af=r.

Sharma, E., Sindhu, J. 2016. Human Resource Development:Indian Banking Vision 2020. Anveshak International Journal of Management, 5(1), 50-60. http://ischolarglobal.com/index.php/aijm/article/view/90308.

Thurber, K.A., Thandrayen, J., Banks, E., Doery, K., Sedgwick, M. and Lovett, R., (2020). Strengths-based approaches for quantitative data analysis: A case study using the australian Longitudinal Study of Indigenous Children. SSM-Population Health. 
Wong, C.A. 2015. Connecting nursing leadership and patient outcomes: state of the science. Journal of Nursing Management, 23(3), 275-278. https://onlinelibrary.wiley.com/doi/pdf/10.1111/jonm.12307.

Yu, S., He, L., Lu, H. 2016. An environmental fairness based optimisation model for the decision-support of joint control over the water quantity and quality of a river basin. Journal of Hydrology, 535, 366-376. https://sciencedirect.com/science/article/pii/s002216941600069x.

Yu, W., Chavez, R., Feng, M., Wong, C.Y., Fynes, B. 2020. Green human resource management and environmental cooperation: An ability-motivation-opportunity and contingency perspective. International Journal of Production Economics, 219, 224235. https://sciencedirect.com/science/article/pii/s0925527319302270.

Zhang, S., Zhang, S., Worrell, E., Crijns-Graus, W., Krol, M., Bruine, M.D., Cofala, J. 2016. Modeling energy efficiency to improve air quality and health effects of China's cement industry. Applied Energy, 184, 574-593.

https://sciencedirect.com/science/article/pii/s0306261916314696. 